\title{
Pseudo-Meigs Syndrome with Ovarian and Abdominal Tuberculosis: A Case Report
}

\author{
${ }^{* 1}$ Alla Satyanarayana Reddy, ${ }^{2}$ Harish Babu, ${ }^{3}$ Lakshmi Sowjanya Tsama and ${ }^{4}$ Narmadha N S \\ ${ }^{1}$ Department of Obstetrics\& Gynaecology, Vinayaka Mission's Medical College \& Hospital, India \\ ${ }^{2}$ Assistant Professor, Department of Obstetrics\& Gynaecology, Vinayaka Mission's Medical College \& Hospital, India \\ ${ }_{3}^{3}$ Junior Resident, Department of Obstetrics\& Gynaecology, Vinayaka Mission's Medical College \& Hospital, India \\ ${ }^{4}$ Senior Resident, Department of Obstetrics\& Gynaecology, Vinayaka Mission's Medical College \& Hospital, India
}

Received: October 23, 2017; Published: October 27, 2017

*Corresponding author: Alla Satyanarayana Reddy, Professor and HOD; Department of Obstetrics and Gynaecology; Vinayaka Mission's Medical College \& Hospital; Karaikal, Pondicherry 609609; Email: drallasreddy@yahoo.co.in

\begin{abstract}
Tuberculosis (TB) is the second leading cause of death from infectious diseases worldwide. In non immuno compromised women, extra pulmonary TB accounts for $20 \%$ of new cases identified .Isolated ovarian TB is an uncommon disease given that genitourinary TB usually presents with endometrial and fallopian tube involvement. We report a case of cystic ovarian mass, with ascites, pleural effusion; tuberculosis of ovary and omentum; third degree utero vaginal prolapse in a post menopausal woman. Ascites and pleural effusion resolved spontaneously in a week of surgery. Patient received ATT and recovered well. Diagnostic difficulties in this case are discussed.
\end{abstract}

Keywords: Extra Pulmonary Tuberculosis; Ovarian Cyst: Ovarian Tuberculosis; Pseudo Meig'S Syndrome

\section{Introduction}

Tuberculosis (TB) is the second leading cause of death from infectious diseases worldwide [1]. Genitourinary TB is the second most common site for extra pulmonary TB [2]. Extra pulmonary TB is common in immuno compromised patients. $20.2 \%$ of the new cases of TB are extra pulmonary. Nine percent of extra pulmonary tuberculosis is accounted by genital tuberculosis [2]. Isolated ovarian TB is an uncommon disease given that genitourinary TB usually presents with endometrial and fallopian tube involvement [3]. Pseudo Meigs syndrome is co existence of pelvic tumour, hydrothorax and ascites. Pseudo Meigs syndrome is clinically important because it resembles metastatic pelvic cancer. Pelvic and peritoneal tuberculosis may resemble advanced ovarian cancer.

\section{Case Report}

Mrs.xxxx aged 50years $\mathrm{P}_{1} \mathrm{~L}_{1}$, post menopausal lady presented at Obstetrics \& Gynaecology department of Vinayaka Mission`s Medical College \& Hospital for mass descending per vagina since 1 year and abdominal distension since 1 year. She is from a low socio economic status, rural, agricultural background. Her last childbirth is 34 years ago. Attained menopause 10 years ago. She is not a known case of hypertension or diabetes mellitus. H/o contact with Pulmonary TB present (neighbour-defaulter and died 6 years ago). Dull looking, thin built woman, cachexic, with BMI $16 \mathrm{~kg} / \mathrm{m}^{2}$. Spine is normal. No lymphadenopathy. On systemic examination-dull note and diminished breath sounds on right lower chest. On abdominal examination-no ventral hernia, no doughy feel of abdomen. Mass of $18 \times 20 \mathrm{~cm}$ arising from pelvis, extending from right iliac fossa to left iliac fossa. Mass is mobile, cystic, mildly tender and lower border of the mass couldn't be felt Minimal ascites.

On Gynaecological examination, third degree UV prolapses with cystocele and rectocele with Keratinization. On bimanual examination uterus atrophic, douglas pouch is full; mass is felt high up, continuous with abdominal mass. Colpocentesis yielded straw coloured fluid. On Ultrasonography--Uterus shows postmenopausal atrophic changes, of size measuring 4.0x2.7x2.1 cm, Myometrium normal and endometrium thin. A large well defined thin walled anechoic midline abdominopelvic cystic lesion seen with multiple septae and internal echoes, with few hyper echoic areas. The mass measured 19x17x10 cm; no calcification. Both ovaries are not imaged. Minimal ascites Serology: HIV-negative Tumor markers found to be
a). Alpha Feto Protein : $0.67 \mathrm{IU} / \mathrm{ml}$
b). Beta HCG : $5.17 \mathrm{mIU} / \mathrm{ml}$
c). CA 125: 213.4 units/ml
d). CA 15-3: 25.7 units $/ \mathrm{ml}$ 


\section{e). CA $19-9:<0.6$ units $/ \mathrm{ml}$}

\section{f). CEA: $1.3 \mathrm{ng} / \mathrm{ml}$}

Chest X Ray-Lungs clear; moderate pleural fluid on right side CT Abdomen revealed well defined abdominopelvic hypodense cystic mass present with few areas of peripheral solid elements, minimal calcification. Mild ascites. Cytology of Ascitic Fluid-negative for malignant cells. Pleural analysis showed no malignant cells. With the team of Gynaecologists and Oncosurgeon- laparomy done. Liver, spleen normal. No adhesions. Moderate ascites. Uterus and tubes are atrophic, no nodularity. Left ovary atrophic. Right ovary is the seat of palpable mass; mass is free from adhesions, cystic, septate with few solid areas. Small areas of papillary projections noted over ovarian mass. No obvious peritoneal nodules. No lymphadenopathy. Small area of rolled up omentum. Bowel wall not involved. Right Ovarian Cystectomy, Salphigectomy, Total Abdominal Hysterectomy with Left Salphingo-Oophorectomy done. Omental and peritoneal biopsy done. Post operatively, 2 units of Albumin infusion and packed cell transfusion done. Histopathological findings- Atrophic endometrium; Myometrium unremarkable; Chronic cervicitis; Serous cystadenoma; Epitheloid granulomas seen in the right ovary; peritoneal biopsy nil significant; Omental tissue showed Tuberculous Granulomas. Post operative period uneventful. Anti tuberculous treatment started during hospital stay. Rifampicin, Isoniazid, Ethambutol and Pyrazinamide daily dose for two months followed by Rifampicin and isoniazid. Ascites and pleural effusion disappeared in a week. At six months post operative, general condition improved; definitive surgery for prolapse is scheduled.

\section{Discussion}

This patient presented with prolapse uterus, cystic ovarian mass with ascites and pleural effusion suggestive of Pseudo-Meigs syndrome and histological evidence of Omental tuberculosis. All other pelvic organs were spared. No definite diagnosis can be made. Genital TB accounts for 5-15\% of infertility. In women with tubal factor of infertility,30-50 \% can have tuberculosis. In genital tuberculosis, fallopian tube is involved in 80-90\%; endometrium in $60-80 \%$; ovary involved in $20-30 \%$ and cervix in $5 \%$ of cases. Tuberculosis of pelvic organs mimics advanced ovarian cancer due to the presence of ascites, complex adnexal masses, peritoneal deposits and raised CA-125 level, especially in peri-and postmenopausal women. Other common features among women with these two conditions are abdominal pain and distension, weight loss and reduced appetite. Pseudo Meigs syndrome is a condition characterised by non malignant ascites and pleural effusion along with pelvic tumours other than solid benign ovarian tumours. Occasionally leiomyomas, stomach and colonic tumours are also seen [4]. It may occur in patients with systemic lupus erythematosis and can have elevated CA125 level [5].

A thorough family history may narrow the differential diagnosis from an infectious etiology, such as TB in patients with multiple family members who had TB, to malignancy in a family history of ovarian cancer [6,7].

In premenopausal women, elevations in CA-125 have been noted in endometriosis, TB, and other non neoplastic diseases.
This makes CA-125 relatively nonspecific and non diagnostic in premenopausal women. CA-125 is elevated in $80 \%$ of postmenopausal ovarian carcinomas. Initial diagnosis of tubo ovarian abscess or ovarian malignancy can be mistaken given the similarities in clinical, radiologic, and serum markers such as an elevated cancer antigen-125, (CA-125) [8]. Sometimes women with pelvic-peritoneal tuberculosis may be subjected to a laparotomy for suspected ovarian cancer which is likely to increase their morbidity [9-13].

\section{Conclusion}

As the treatment of pelvic-peritoneal tuberculosis is completely different from that of ovarian cancer, it is important to reach a correct diagnosis. An effort should be made to obtain a cytological or histopathological diagnosis of either condition by ultrasound guided needle biopsy or laparoscopically obtained biopsy rather that proceeding with laparotomy for suspected ovarian cancer.

\section{References}

1. Gill MK, Bains SPS, Rana S (2011) Isolated ovarian tuberculosis: case report and literature review. Int J Health Allied Sci 5(1): 7-10.

2. Yebouet E, Olivier MM, Koui S, Bankole SR (2015) Ovarian tuberculosis mimicking a malignant tumour. Afr J Paediatr Surg 12(2): 155-157.

3. Yamamoto A, Miyasaka Y, Furuya K, Hideki Watanabe, Masahiro Maruyama et al. (2016) Pseudo-Meigs' syndrome due to ovarian metastases from colon cancer: a case report and review of the literature. Surg Case Rep 2(1): 112.

4. Dalvi SR, Yildirim R, Santoriello D (2012) Pseudo-pseudo Meigs' syndrome in a patient with systemic lupus erythematosus. Lupus 21(13): 1463-1466.

5. Lee SY, Lee SW, Chung WT (2013) Severe inflammation may be caused by hyperferritinemia of pseudo-pseudo Meigs' syndrome in lupus patients: two cases reports and a literature review. ClinRheumatol 32(12): 18231826.

6. Farzaneh F, Yassaee F (2009) Familial tuberculosis mimicking advanced ovarian cancer. Infect Dis Obstet Gynecol 2009(2009): 5.

7. Dogan E, Altunyurt S, Altindag T, Onvural A (2004) Tubo-ovarian abscess mimicking ovarian tumor in a sexually inactive girl. J PediatrAdolesc Gynecol 17(5): 351-352.

8. Manidakis LG, Angelakis E, Sifakis S, et al. (2001) Genital tuberculosis can present as disseminated ovarian carcinoma with ascites and raised Ca-125: a case report. GynecolObstet Invest 51(4): 277-227.

9. A Mahdavi, VK Malviya, BRHerschman (2007) Peritonealtuberculosis disguised as ovarian cancer: an emerging clinical challenge. Gynecologic Oncology 84(1): 167-170.

10. F Yassaee, F Farzaneh (2009) Familial tuberculosis mimicking advanced ovarian cancer. Infectious Diseases in Obstetrics and Gynecology 2009(2009): 5 .

11. CH Wu, CC ChangChien, CW Tseng, HY Chang, YC Ou, et al. (2011) Disseminated peritoneal tuberculosis simulating advanced ovarian cancer: a retrospective study of 17 cases. Taiwanese Journal of Obstetrics and Gynecology 50(3): 292-296.

12. S Imtiaz, N Siddiqui, M Ahmad, A Jahan (2012) Pelvicperitoneal tuberculosis mimicking ovarian cancer. Journal of the College of Physicians and Surgeons Pakistan 22(2): 113-115.

13. (2013) WHO Global Tuberculosis Report: World Health Organization Geneva, Switzerland. 


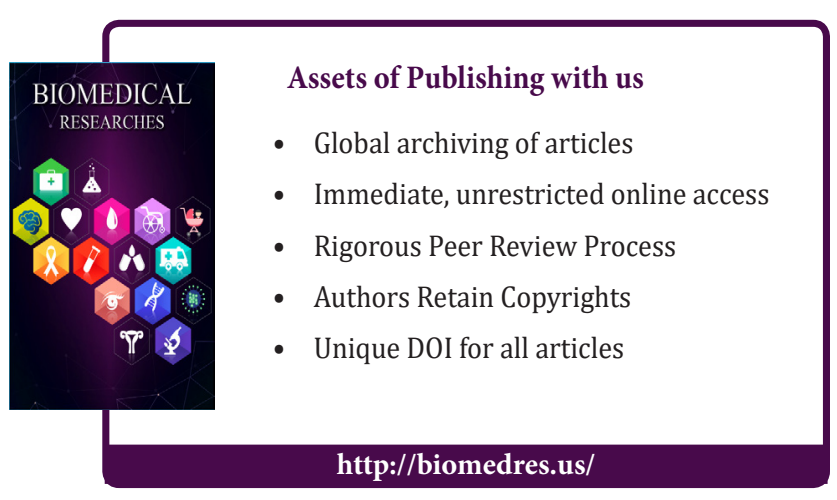

